University of Nebraska - Lincoln

DigitalCommons@University of Nebraska - Lincoln

November 2000

\title{
Electrophysiological studies of olfaction in the whip spider Phrynus parvulus (Arachnida, Amblypygi)
}

\author{
Eileen Hebets \\ University of Nebraska - Lincoln, ehebets2@unl.edu \\ Reginald F. Chapman \\ University of Arizona, Tucson, AZ
}

Follow this and additional works at: https://digitalcommons.unl.edu/bioscihebets

Part of the Behavior and Ethology Commons

Hebets, Eileen and Chapman, Reginald F., "Electrophysiological studies of olfaction in the whip spider Phrynus parvulus (Arachnida, Amblypygi)" (2000). Eileen Hebets Publications. 19.

https://digitalcommons.unl.edu/bioscihebets/19

This Article is brought to you for free and open access by the Papers in the Biological Sciences at DigitalCommons@University of Nebraska - Lincoln. It has been accepted for inclusion in Eileen Hebets Publications by an authorized administrator of DigitalCommons@University of Nebraska - Lincoln. 
Published in Journal of Insect Physiology 46:11 (November 2000), pp. 1441-1448; doi 10.1016/Soo22-1910(oo)ooo68-8

Copyright (C) 2000 Elsevier Science Ltd. Used by permission. http://www.sciencedirect.com/science/journal/o0221910

Submitted January 21, 2000; accepted April 6, 2000; published online July 10, 2000.

\title{
Electrophysiological studies of olfaction in the whip spider Phrynus parvulus (Arachnida, Amblypygi)
}

\author{
Eileen A. Hebets ${ }^{1}$ and Reginald F. Chapman ${ }^{2}$ \\ ${ }^{1}$ Department of Ecology and Evolutionary Biology, University of Arizona, \\ Tucson, AZ 85721, USA (Corresponding author) \\ ${ }^{2}$ Division of Neurobiology, University of Arizona, Tucson, AZ 85721, USA
}

\begin{abstract}
The olfactory response of the whip spider Phrynus parvulus from Costa Rica was examined using a technique analogous to that used for insect electroantennograms on the tarsi of the antenniform legs which bear multiporous sensilla. Responses to 42 chemicals representing different chain lengths of alkanes, carboxylic acids, alcohols, aldehydes, and ketones, as well as some esters, monoterpenes, and phenolics were examined. Fifty-four percent of the chemicals tested elicited responses. Concentration-response curves were generated for guaiacol, hexanal, methyl salicylate, benzaldehyde, octanoic acid, and linalool. Guaiacol, benzaldehyde, and hexanol elicited the greatest responses and no differences were detected between the sexes. Compounds with chain lengths of six carbon atoms generated strong responses and most monocarboxylic acids and ring compounds elicited responses. Some compounds produced increases in potential believed to arise from a hyperpolarizing effect on the neurons. The broad spectrum of chemicals to which these animals respond is similar to results of other studies examining the general olfactory sense of insects. It is possible that odor learning plays a significant role in the behavior of amblypygids.
\end{abstract}

Keywords: amblypygid, arachnid, Phrynus, olfaction, electrophysiology

\section{Introduction}

The use of chemicals for information transfer is thought to be the oldest form of animal communication and the reliance on chemical cues for intra- and inter-specific signaling and information gathering plays an important role in the lives of many organisms (Bradbury and Vehrencamp, 1998). Most studies of insect olfaction have focused on responses to highly specific stimuli such as pheromones or host odors (Dickens et al., 1993; Bartelt et al., 1995; Chambers et al., 1996; Raguso et al., 1996; Honda et al., 1998; Zhu et al., 1999). The specificity of responses to particular odors such as pheromones has been well documented in insects and has led to a more general understanding of sensory detection and processing. However, when a broad range of chemicals is used to test olfactory responses, insects seem to respond to a wide variety of compounds, suggesting the presence of a more general olfactory capability in addition to specializations for certain chemicals (Topazzini et al., 1990; Raguso et al., 1996; Sant'Ana and Dickens, 1998).

The central processing of olfactory inputs via glomeruli to the mushroom bodies of the brain (which are thought to function in learning and memory) suggests that behavioral responses to odors may arise from learned associations. The relative sizes of arthropod mushroom bodies vary tremendously and are thought to be correlated to a certain degree with olfactory capability as well as learning and memory. Most arthropods possess mushroom bodies but in the arachnid order Amblypygi the mushroom bodies are so large and convoluted that "they appear to have miniaturized other brain neuropils" (Strausfeld et al., 1998). The enlarged size of amblypygid mushroom bodies suggests that odor recognition and associated learning may be very important in the lives of these nocturnal animals. 
The importance of olfaction for arachnids in general has not been well studied and, thus, is not well understood. Although it is generally accepted that spiders possess the ability to smell, or to detect airborne chemicals, there is still debate as to the location and form of a spider's odor receptors and most of the studies indicating the olfactory abilities of spiders are based upon behavioral observations alone (Foelix, 1996). According to both the structural morphology of particular sensillum types and studies of the neuroanatomy of different arachnid groups, it seems likely that there are other orders in which the ability to smell is important, but the degree to which their olfactory capabilities are developed remains unknown. Members of the order Acari, mites and ticks, possess multiporous sensilla with a demonstrated olfactory function (Waladde, 1982) and it has been well documented that pheromones and semiochemicals play important roles in mating behavior and host finding of these animals (Sonenshine, 1985; Hamilton et al., 1989; De Bruyne and Guerin 1994, 1998). Electrophysiological studies have also been conducted on the pectines of scorpions demonstrating that these animals can perceive a wide range of olfactory stimulants (Gaffin and Brownell, 1997).

Since no chelicerates possess antennae, their olfactory glomeruli instead reside in segmental neuromeres associated with other appendages (Strausfeld et al., 1998). In both amblypygids (whip spiders) and uropygids (vinegaroons or whip scorpions) the first pair of legs are elongated into antenniform appendages. The antenniform legs of amblypygids possess hundreds of sensilla encompassing a variety of receptor types including two different types of multiporous sensilla that resemble the olfactory sensilla of insects. The structure and arrangement of the associated sensory neurons are basically the same as those occurring in insect olfactory sensilla (Altner and Prillinger, 1980) and the presumed function of these sensilla is olfactory but this has never been demonstrated experimentally (Foelix et al., 1975; Igelmund, 1987). Due to both the presence of large numbers of presumed olfactory sensilla and the fact that the amblypygid mushroom body is extremely large and well developed, one might predict that the olfactory capability of amblypygids is also extremely well developed.

This study examines the olfactory capabilities of the amblypygid Phrynus parvulus using an electrophysiological technique analogous to the electroantennogram (EAG) of insects. Because the experiments involve the modified first walking legs of the animals, the records are referred to as electrolegograms (ELGs). The responses of individuals of both males and females were recorded to a series of compounds representing different chemical classes.

\section{Materials and methods}

\subsection{Animals}

Individuals of Phrynus parvulus were collected at night from the arboretum at La Selva Biological Station, Costa Rica, and brought to the laboratory at the University of Arizona where they were housed individually in plastic containers, width $9 \mathrm{~cm}$ and height $11 \mathrm{~cm}$. Inside the containers, pieces of screening were taped to two of the walls to provide a vertical surface upon which the amblypygids could climb. Holes were burned into the bottom of the containers through which cotton wicks were placed. The cages were placed on top of reservoirs of water so that half of the cotton wicks sat in the water and the other half remained inside the cage. This design allowed a constant source of water and increased humidity inside the cages. Individuals were kept in an environment chamber on a L12:D12 light cycle at a temperature between 27 and $30^{\circ} \mathrm{C}$. The light cycle was reversed so that the lights were out during the day and on throughout the night. Individuals were fed 2-3 live crickets once a week.

\subsection{Chemicals}

All chemicals were obtained from commercial sources (Aldrich, Sigma). The 42 chemicals chosen as olfactory stimuli are shown in Table 1 and included varying chain lengths of monocarboxylic acids, aldehydes, alcohols, and acetates, along with some monoterpenes, and phenolic compounds. All chemicals were dissolved in hexane to give loadings on the delivery filter paper of $10^{-3}$ g. Concentration series were also prepared for guaiacol, hexanal, benzaldehyde, octanoic acid, linalool, and methyl salicylate to give loadings upon delivery of $10^{-3}$, $10^{-4}, 10^{-5}, 10^{-6}$, and $10^{-7} \mathrm{~g}$.

\subsection{Electrophysiology}

All recordings were made in the first four hours of the animal's scotophase starting at 0800 hours local time. ELGs were measured and recorded using a Syntech INR2 portable recording unit in the laboratory. Approximately $15 \mathrm{~mm}$ of the distal portion of the antenniform leg of a test animal comprising the distal 27 tarsal annuli was cut off and then the most distal annulus of this cut piece was removed. The two ends of the excised piece of antenniform leg were inserted into microcapillaries on the recording unit, with the distal end in the different electrode, so that approximately $9 \mathrm{~mm}$ of tarsus remained exposed. This is the portion of the leg bearing the putative olfactory receptors. The hemolymph in the leg was in continuity with the saline solution that filled the microcapillaries. Because there is no information on the ionic composition of amblypygid hemolymph, the 
Table 1. Chemicals used in the experiments, the numbers of animals tested, electrolegogram responses at a loading of $10^{-3} \mathrm{~g}$ relative to the response to guaiacol, and vapor pressures at $24^{\circ} \mathrm{C}$.

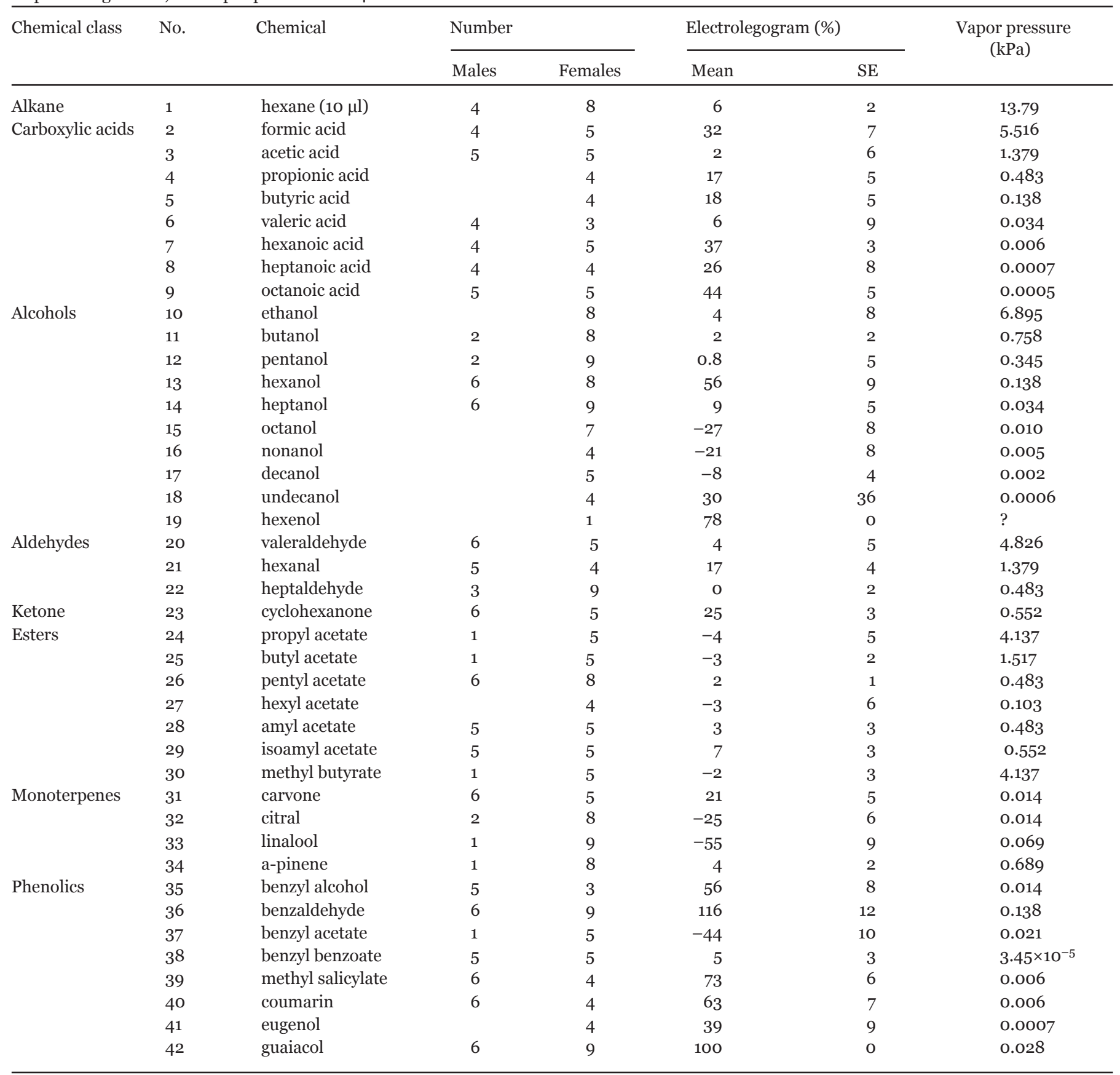

saline was one commonly used for physiological experiments with Manduca sexta (150 $\mathrm{mM} \mathrm{NaCl}, 3 \mathrm{mM} \mathrm{CaCl}_{2}$, $3 \mathrm{mM} \mathrm{KCl}, 10 \mathrm{mM}$ TES (N-tris[Hydroxymethyl]methyl -2-aminoethanesulfonic acid) buffer, $\mathrm{pH}$ 6.9; modified from Pichon et al., 1972). The saline was connected via silver wire to the amplifier and computer.

The part of the leg between the microcapillaries was bathed continuously in an airflow of $650-700 \mathrm{ml} / \mathrm{min}$ delivered through an 8-mm diameter glass tube with a side port through which odors were injected into the air stream. At this airspeed, an injection of air alone produced little or no signal after the mechanoreceptors of the leg had adapted (see Figure 2a). The air was charcoal-filtered and humidified and its temperature was approximately $24^{\circ} \mathrm{C}$. Immediately prior to testing, $10 \mu \mathrm{l}$ of the test chemical solution were pipetted on to a piece of Whatman No. 1 filter paper $(\sim 3 \mathrm{~mm} \times 14 \mathrm{~mm})$. The filter paper was exposed to the air for $30 \mathrm{~s}$ to allow the hexane to evaporate, then placed inside a Pasteur pipette and attached to a syringe with an automated, motor-driven de- 
livery system. Before the pipette was connected to the airflow over the leg, $5 \mathrm{ml}$ of air were expressed in $1 \mathrm{~s}$ to evacuate the odor-laden air in the pipette. After a $30 \mathrm{~s}$ pause, $5 \mathrm{ml}$ was injected in $1 \mathrm{~s}$ into the airflow to stimulate the leg. In this way, the time for evaporation of each test chemical in the pipette was standardized. Each test animal only received one $5-\mathrm{ml}$ dose of each chemical. The continuous flow of clean air over the preparation ensured that odors were immediately removed from its vicinity.

Due to the diminished responsiveness of the antenniform leg over time, standards $\left(10^{-3} \mathrm{~g}\right.$ guaiacol) and blanks (air) were included after every fifth or sixth chemical tested. The response to hexane was also tested every twelfth stimulus. The time interval between chemical stimuli was approximately $2 \mathrm{~min}$. No preparations were used for more than $2 \mathrm{~h}$. During this time the response to the guaiacol standard declined on average to about 50\% of its original value.

Data were recorded directly on to a computer from which it was possible to read off the voltage of the signal. The decline in response to the guaiacol standard was approximated to a straight line and the responses to other chemicals or concentrations were expressed as a percentage of the response to the standard after subtracting any mechanosensory signal produced by air alone. A total of six males and nine females were tested but all 42 chemicals, along with all six concentration series, were not tested on each individual and thus the sample sizes for each chemical stimulus vary. Attempts were also made to record electrolegograms from the basal half of the tarsus of the antenniform leg of three individuals. There are no multiporous sensilla on this part of the leg.

Statistical procedures were carried out with the JMP® Start statistics program.

\section{Results}

The magnitude of the response to guaiacol at a loading of $10^{-3} \mathrm{~g}$ on the filter paper was similar in the two sexes [males, $0.78 \pm 0.09 \mathrm{mV}$ (mean \pm standard error); females, $0.59 \pm 0.08 \mathrm{mV} ; t=1.569,13 \mathrm{df}, P=0.141]$. With 22 other chemicals, three or more animals of each sex were tested. Analysis of variance on transformed data to account for lack of normality showed no difference in the relative responses of the sexes to any of the chemicals (Compound, $F=15.3243, P<0.0001$; Sex, $F=0.1978$, $P=0.657$; Sex $\times$ Compound, $F=1.1609, P=0.290)$ and data for both sexes are combined in the following analyses. Responses to odor were only obtained with distal parts of the tarsus; experiments with proximal regions gave no evidence of olfactory sensitivity.

Three types of response are separated. Chemicals which gave mean ELGs within $\pm 10 \%$ of zero often had standard errors which overlapped zero and these are considered to have produced no signal. Based on this criterion, 19 of the chemicals failed to stimulate the sensilla (Table 1). Eighteen of the chemicals produced a significant downward deflection indicative of a reduction in potential and comparable with that produced in a typical insect EAG (Figure 2b). By analogy with insect studies, we infer that such a response by the sensory neurons would lead to the production of action potentials and we refer to it as "excitatory". Five chemicals produced an upward deflection (Figure 2c,d), an increase in potential, and such deflections we refer to as "inhibitory".

The magnitudes of ELG responses relative to the guaiacol standard for all the compounds tested at a loading on the filter paper of $10^{-3} \mathrm{~g}$ are given in Table 1 and Figure 1 in relation to vapor pressure of the compounds at $24^{\circ} \mathrm{C}$. Excitatory responses were obtained to compounds of vapor pressures between 0.0005 and 5.516 $\mathrm{kPa}$ and the signals produced were usually of the type shown in Figure 2b. Within this same range of vapor pressures and chemical loading, other compounds produced no signal and some consistently gave inhibitory responses (Figure 2c).

The compounds with inhibitory ELG responses were octanol, nonanol, citral, linalool, and benzyl acetate. When the orientation of the leg between the electrodes was reversed, the signal was also reversed for all these compounds (Figure 2c,d). No response was elicited by these compounds when the leg was allowed to dry. Figure 3 shows the dose response for linalool.

All the monocarboxylic acids tested produced positive ELGs with octanoic acid producing the greatest response (Figure 4a). A loading of $10^{-7} \mathrm{~g}$ failed to elicit a response but above this the magnitude of the ELG reached a plateau above $10^{-5} \mathrm{~g}$ (Figure 3 ). Of the primary

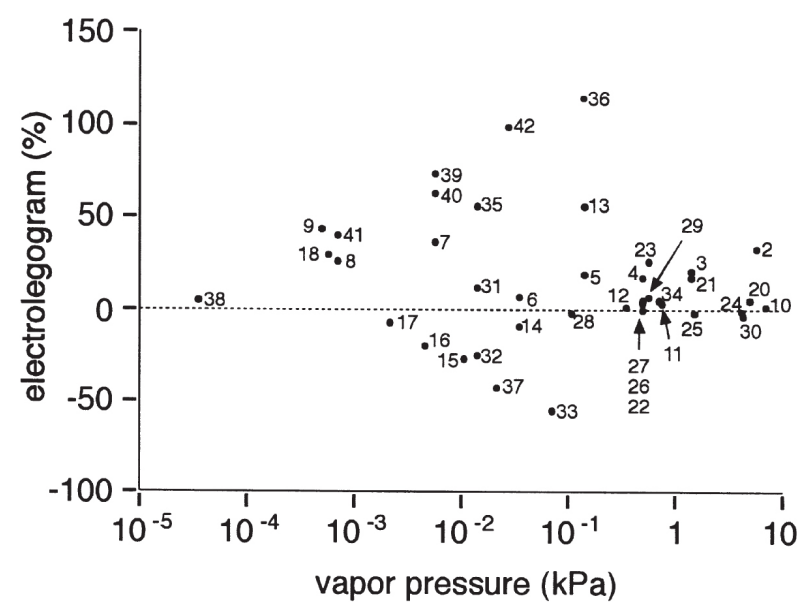

Figure 1. Electrolegogram responses (relative to guaiacol standard) to different compounds at loadings of $10^{-3} \mathrm{~g}$ on the filter paper in relation to their vapor pressure at $24^{\circ} \mathrm{C}$. Compounds are numbered as in Table 1 and each point is the mean response of the sum of males and females given in the table. In Figure 1, Figure 3 and Figure 4, positive values represent downward deflections of the ELG (excitation), negative values represent upward deflections as in Figure 2c (inhibition). 

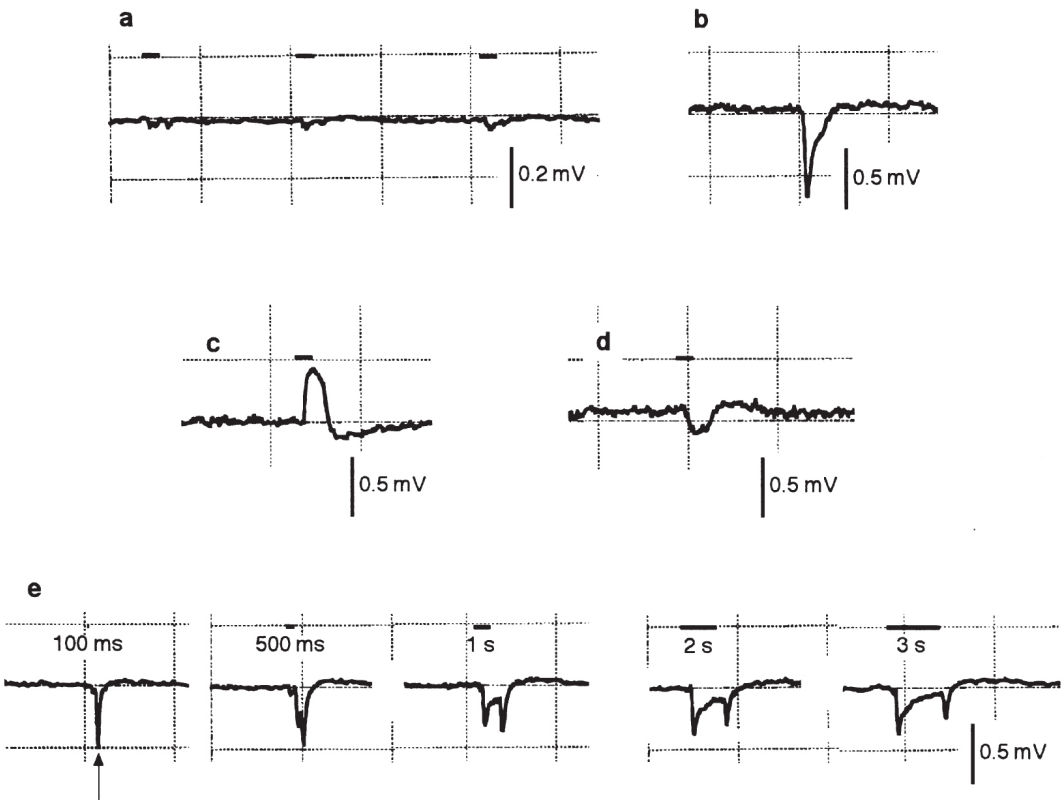

Figure 2. Examples of electrolegogram responses all at a loading of $10^{-3} \mathrm{~g}$ on the filter paper. Upper bars show stimulus duration. Except in (e), this was $1 \mathrm{~s}$. (a) Responses to three air puffs. (b) Response to benzaldehyde. Most responses were of this type. (c) Inhibitory signal produced by linalool. (d) Reversal of response to linalool when the position of the leg was reversed between the electrodes. (e) Bimodal response to guaiacol. The timing of the off-response was dependent on stimulus duration (upper bars). Note that at very short durations the on- and off-responses were additive (arrow).
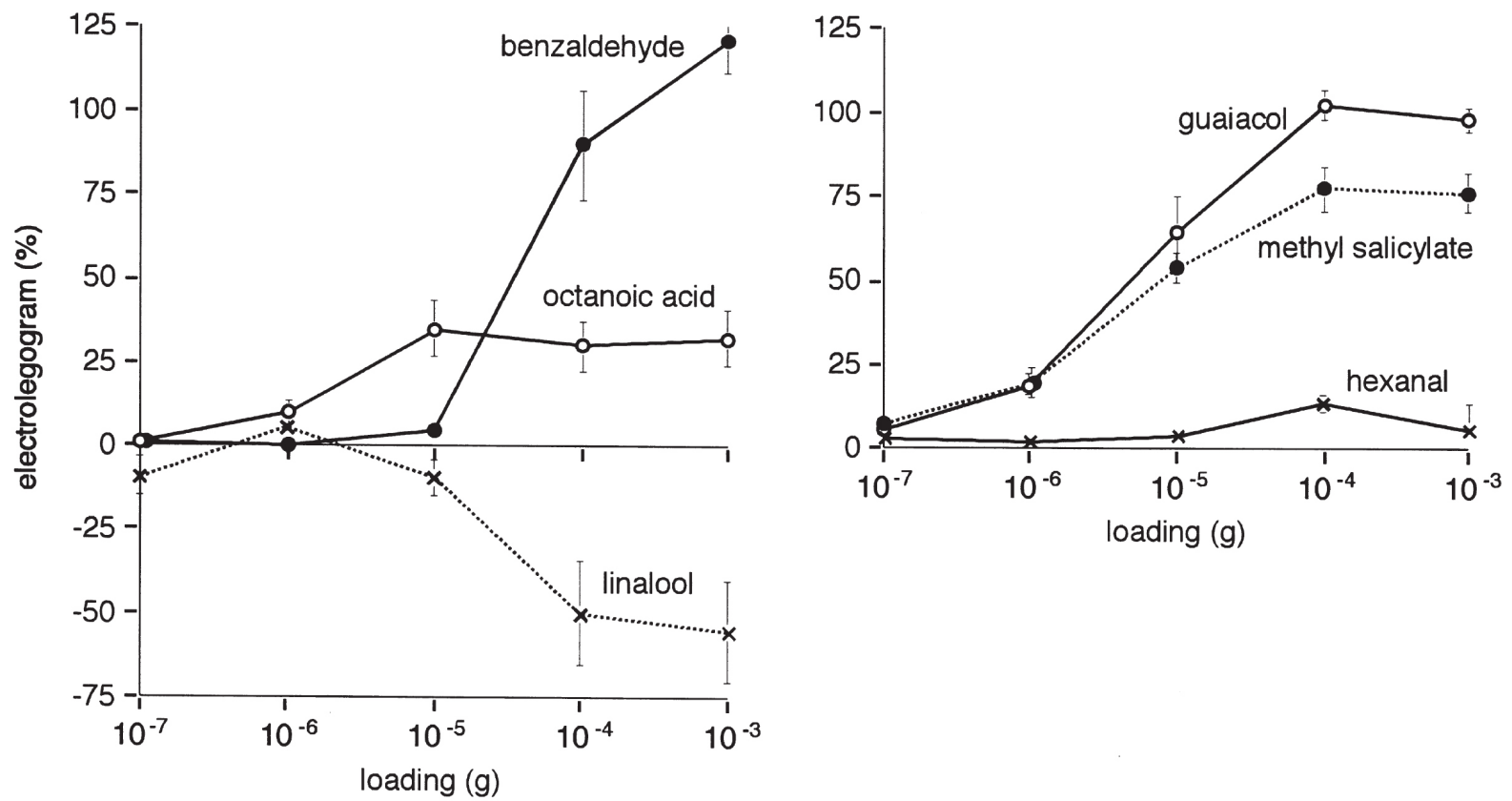

acol and benzaldehyde, $n=8$; all others, $n=4$.

alcohols tested, only hexanol gave a consistent excitatory ELG while both octanol and nonanol gave inhibitory signals (Figure 4b). The response to undecanol was variable. A single animal tested with hexenol gave a strong excitatory signal.
Three straight-chain aldehydes were tested (Table 1) but only hexanal produced a signal. The response had a threshold close to $10^{-5} \mathrm{~g}$ and reached a maximum at $10^{-4}$ $\mathrm{g}$ (Figure 3). The only ketone tested was cyclohexanone; it produced a moderate signal. None of the acetates ex- 
cept benzyl acetate (see below) produced a response, nor did methyl butyrate.

Four monoterpenes were tested. Carvone produced a small excitatory signal, *-pinene had no effect, while citral and linalool both elicited inhibitory signals. The threshold of response to linalool was close to $10^{-5} \mathrm{~g}$ loading, with a plateau above $10^{-4} \mathrm{~g}$ (Figure 3).

All the phenolic compounds except benzyl benzoate produced moderate to strong responses, all of which were excitatory except for benzyl acetate. The magnitude of response to benzaldehyde was similar to that to guaiacol. The latter always produced a bimodal signal with a second sharp downward deflection (off effect) when the stimulus was removed (Figure 2e). The size of the second peak varied independently of the first peak. The threshold of response to benzaldehyde occurred at a loading close to $10^{-5} \mathrm{~g}$, but sensitivity to guaiacol and methyl salicylate was much greater with thresholds at or below $10^{-7}$. The response to these two compounds plateaued at loadings above $10^{-4} \mathrm{~g}$ (Figure 3 ).
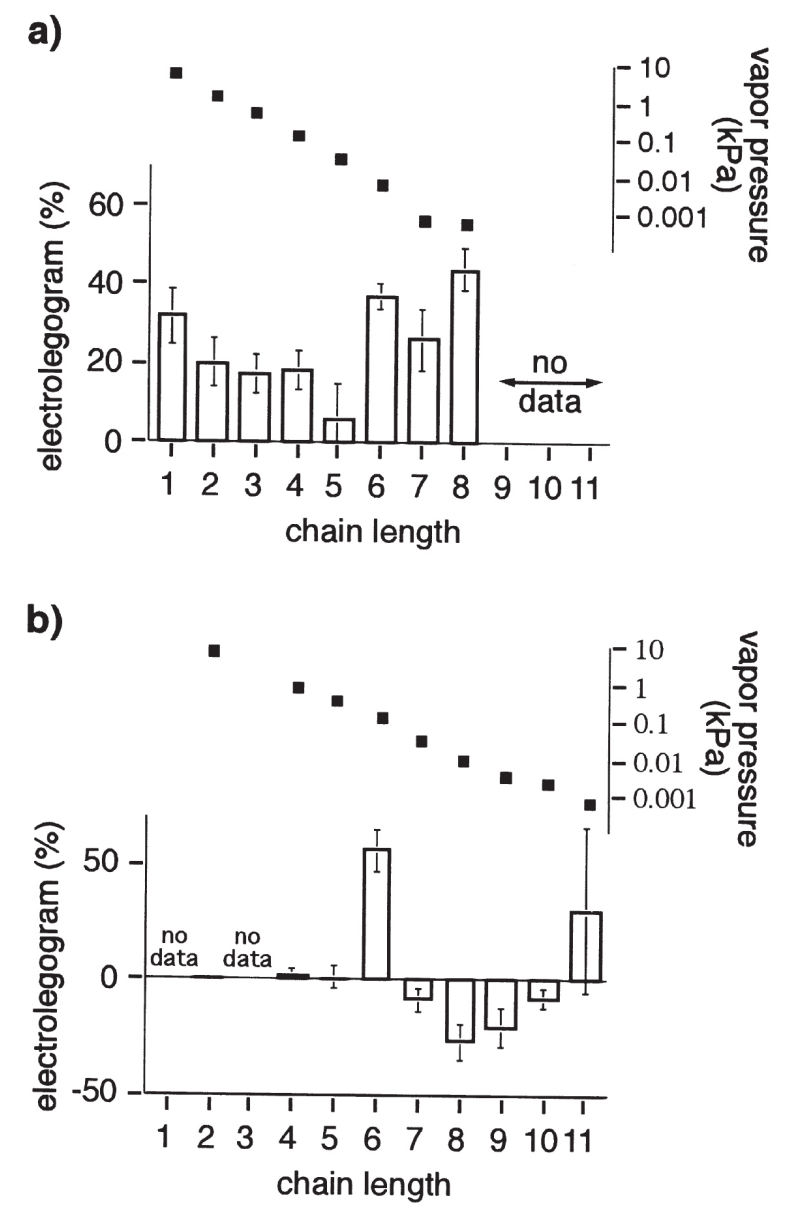

Figure 4. Electrolegogram responses (mean \pm standard error, relative to guaiacol standard) for (a) monocarboxylic acids and (b) primary alcohols of varying chain lengths and the approximate vapor pressures at $24^{\circ} \mathrm{C}$. Values for $n$ are the sums of males and females in Table 1.

\section{Discussion}

Our results show that $P$. parvulus is sensitive to odors in a number of chemical classes and strongly support the putative olfactory function of multiporous sensilla on the distal annuli of the antenniform legs. No evidence of an olfactory response was obtained from parts of the leg where these sensilla were absent.

\subsection{Vapor pressure}

The chemicals used in this study vary greatly in their volatility. Based upon our experimental methodology, differences in chemical volatilities could have greatly influenced our results. In order to take some account of differences in volatility, we obtained vapor pressures for most of our test chemicals from Yaws (1994) (see Table 1). Hexane, which was used as our solvent, has a vapor pressure at $24^{\circ} \mathrm{C}$ of $13.79 \mathrm{kPa}$ and Brockerhoff and Grant (1999) found that it had completely evaporated from similar-sized pieces of filter paper after $30 \mathrm{~s}$. Thus, based upon our protocol, hexane should never have been present at the time of test odor delivery and when hexane alone was tested no response was elicited.

In examining Figure 1, it is clear that most of our results are not likely to be confounded by differences in vapor pressure. None of the chemicals used in our study had a higher volatility than hexane. Formic acid has a relatively high vapor pressure, yet it elicited a fairly strong response, indicating that it was still present in the syringe upon odor delivery (Figure 1, chemical no. 2). It seems likely that non-responses in the vapor pressure range between 0.001 and $10 \mathrm{kPa}$ are true non-responses and not an artifact of the chemical being evaporated off. Most of the chemicals were only tested at one loading, $10^{-3} \mathrm{~g}$, and it is possible that a response would have been obtained at higher concentrations. However, the six chemicals for which dose responses were obtained had thresholds at loadings well below $10^{-3} \mathrm{~g}$, and concentrations above this may not be biologically relevant.

Another concern is that chemicals with low volatility may not have volatilized enough in the syringe at the time of odor delivery to produce a response. However, this seems unlikely since there are four chemicals with vapor pressures between 0.0001 and $0.001 \mathrm{kPa}$ that do elicit strong responses. Except for benzyl benzoate (Figure 1 , no. 38), we feel confidant that all of our non-responses are real and not artifacts of vapor pressure differences. The magnitudes of responses, however, will have been affected because numbers of molecules delivered over the legs will have varied between compounds in a manner which we cannot predict. 


\subsection{Putative inhibitory signals}

As far as we are aware, inhibitory responses have not been documented in insect electroantennograms but there are numerous examples of inhibition of the spontaneous activity of olfactory receptor neurons (for example, Anderson et al., 1995; Den Otter and Van der Goes van Naters, 1993). In a few cases, an accompanying hyperpolarization of the neuronal membrane has also been demonstrated (Den Otter et al., 1980; Pophof, 1997). If a sufficient number of neurons responded in this way they would be expected to produce an increase in the potential recorded by an electroantennogram. We believe that the increases in potential we have observed in ELGs of $P$. parvulus are a result of such hyperpolarizations of cells in the leg and are not artifacts. Linalool produced a typical but inverted increase in response as concentration was increased; reversing the orientation of the leg between the electrodes produced a reversal of the signal; and the signal was lost once the leg died. These results are consistent with a real biological phenomenon and would not be expected if the effect was simply some physical artifact.

\subsection{Guaiacol off-effect}

The off-effect observed in response to guaiacol is also a genuine biological effect. None of the other chemicals, nor air alone, produced an off-effect so it is not simply an electrical artifact of the switching system. Den Otter et al. (1980) depict an off-effect (which they call a rebound) in a single olfactory receptor cell after inhibition by pure butyric acid and off-effects in interneurons are common (see, for example, Christensen and Hildebrand, 1987). Since the antenniform legs of amblypygids contain the cell bodies of giant interneurons, some of which may have connections with olfactory neurons (Igelmund and Wendler, 1991), it is possible that the effect we observed derives from the activity of these cells rather than the sensory neurons themselves.

\subsection{Ecological significance}

The chemicals to which $P$. parvulus exhibited responses are all commonly occurring in the environment, most of them being produced by plants (see, for example, Gibbs, 1974) and some possibly by animals. As with many insects (for example, Dickens et al., 1993; Chinta et al., 1994; Thiery and Marion-Poll, 1998), P. parvulus responds to a number of six-carbon-atom compounds which are common components of green leaf odor, but the strongest responses were those to a number of phenolic compounds. The amblypygids are generalist predators and are found in association with a wide variety of trees, and we believe that none of the compounds producing large ELG responses is likely to have specific importance to the animals in the field (E. A. Hebets, unpublished observations). Based upon the olfactory capabilities demonstrated in this study, as well as the extensive development of the mushroom bodies of amblypygids, it seems possible that olfactory learning plays a major role in the biology of these animals.

\section{Acknowledgements}

We are especially grateful to Dr. Ann Fraser who allowed us to use the equipment and helped us to develop a satisfactory technique for our animals. She also made helpful comments on an early draft of the manuscript. Dr. Tom Christensen was always ready with advice and Karen Ober gave practical help. E. A. Hebets was funded by awards from the National Science Foundation Research Training Grant to the Department of Ecology and Evolutionary Biology, University of Arizona, from the Organization for Tropical Studies and from the Animal Behavior Society.

\section{References}

Altner, H., and Prillinger, L., 1980. Ultrastructure of invertebrate chemo-, thermo-, and hygroreceptors and its functional significance. International Review of Cytology 67 , pp. 69-139.

Anderson, P., Hansson, B. S., and Lofqvist, J., 1995. Plantodour-specific receptor neurones on the antennae of female and male Spodoptera littoralis. Physiological Entomology 2o, pp. 189-198.

Bartelt, R. J., Weaver, D. K., and Arbogast, R. T., 1995. Aggregation pheromone of Carpophilus dimidiatus (F.) (Coleoptera: Nitidulidae) and responses to Carpophilus pheromones in South Carolina. Journal of Chemical Ecology 21, pp. 1745-1762.

Bradbury, J. W., and Vehrencamp, S. L., 1998. Principles of Animal Communication, Sinaur Associates, Sunderland, MA.

Brockerhoff, E. G., and Grant, G. G., 1999. Correction for differences in volatility among olfactory stimuli and effect on EAG responses of Dioryctria abietivorella to plant volatiles. Journal of Chemical Ecology 25, pp. 1353-1367.

Chambers, J., Van Wick, C. B., White, P. B., Gerrard, C. M., and Mori, K., 1996. Grain weevil: Sitophilus granarius (L.): antennal and behavioral responses to male-produced pheromones. Journal of Chemical Ecology 22, pp. 1639-1654.

Chinta, S., Dickens, J. C., and Aldrich, J. R., 1994. Olfactory reception of potential pheromones and plant odors by tarnished plant bug, Lygus lineolaris (Hemiptera Miridae). Journal of Chemical Ecology 2o, pp. 3251-3267.

Christensen, T. A., and Hildebrand, J. G., 1987. Male-specific, sex pheromone projection neurons in the antennal lobes of the moth Manduca sexta. Journal of Comparative Physiology A 160, pp. 553-569.

De Bruyne, M., and Guerin, P. M., 1994. Isolation of 2,6-dichlorophenol from the cattle tick Boophilus microplus: receptor cell responses but no evidence for a behavioural response. Journal of Insect Physiology 4o, pp. 143-154. 
De Bruyne, M., and Guerin, P. M., 1998. Contact chemostimuli in the mating behaviour of the cattle tick, Boophilus microplus. Archives of Insect Biochemistry and Physiology 39, pp. 65-80.

Den Otter, C. J., Behan, M., and Maes, F. W., 1980. Single cell responses in female Pieris brassicae (Lepidoptera, Pieridae) to plant volatiles and conspecific egg odours. Journal of Insect Physiology 26, pp. 465-472.

Den Otter, C. J., and Van der Goes van Naters, W. M., 1993. Responses of individual antennal olfactory cells of tsetse flies (Glossina m. morsitans) to phenols from cattle urine. Physiological Entomology 18, pp. 43-49.

Dickens, J. C., Visser, J. H., and Van der Pers, J. N. C., 1993. Detection and deactivation of pheromone and plant odor components by the beet armyworm, Spodoptera exigua (Hubner) (Lepidoptera Noctuidae). Journal of Insect Physiology 39, pp. 503-516.

Foelix, R. F., 1996. Biology of Spiders (2nd edn ed.),, Oxford University Press, Oxford.

Foelix, R. F., Chu-Wang, I.-Wu., and Beck, L., 1975. Fine structure of tarsal sensory organs in the whip spider $A d-$ metus pumilio (Amblypygi Arachnida). Tissue and Cell 7 , pp. 331-346.

Gaffin, D. D., and Brownell, P.H., 1997. Response properties of chemosensory peg sensilla on the pectines of scorpions. Journal of Comparative Physiology A 181, pp. 291-300.

Gibbs, R. D., 1974. Chemotaxonomy of Flowering Plants, McGill-Queen's University Press, Montreal (4 volumes).

Hamilton, J. G. C., Sonenshine, D. E., and Lusby, W. R., 1989. Cholesteryl oleate: mounting sex pheromone of the hard tick Dermacentor variabilis (Say) (Acari: Ixodidae). Journal of Insect Physiology 35, pp. 873-879.

Honda, K., Omura, H., and Hayashi, N., 1998. Identification of floral volatiles from Ligustrum japonicum that stimulate flower-visiting by cabbage butterfly, Pieris rapae. Journal of Chemical Ecology 24, pp. 2167-2180.

Igelmund, P., 1987. Morphology, sense organs, and regeneration of the forelegs (whips) of the whip spider Heterophrynus elaphus (Arachnida Amblypygi). Journal of Morphology 193, pp. 75-89.

Igelmund, P., and Wendler, G., 1991. The giant fiber system in the forelegs (whips) of the whip spider Heterophrynus ela- phus Pocock (Arachnida: Amblypygi). Journal of Comparative Physiology A 168, pp. 63-73.

Pichon, Y., Sattelle, D. B., and Lane, N. J., 1972. Conduction processes in the nerve cord of the moth Manduca sexta in relation to its ultrastructure and haemolymphionic composition. Journal of Experimental Biology 56, pp. 717-734.

Pophof, B., 1997. Olfactory responses recorded from sensilla coeloconica of the silkmoth Bombyx mori. Physiological Entomology 22, pp. 239-248.

Raguso, R. A., Light, D. M., and Pickersky, E., 1996. Electroantennogram responses of Hyles lineata (Sphingidae: Lepidoptera) to volatile compounds from Clarkia breweri (Onagraceae) and other moth-pollinated flowers. Journal of Chemical Ecology 22, pp. 1735-1766.

Sant'Ana, J., and Dickens, J. C., 1998. Comparative electrophysiological studies of olfaction in predaceous bugs. Journal of Chemical Ecology 24, pp. 965-983.

Sonenshine, D. E., 1985. Pheromones and other semiochemicals of the acari. Annual Review of Entomology 30, pp. $1-28$.

Strausfeld, N. J., Hansen, L., Li, Y., Gomez, R. S., and Ito, K., 1998. Evolution, diversity, and interpretations of arthropod mushroom bodies. Learning and Memory 5, pp. 11-37.

Thiery, D., and Marion-Poll, F., 1998. Electroantennogram responses of Douglas fir seed chalcids to plant volatiles. Journal of Insect Physiology 44, pp. 483-490.

Topazzini, A., Mazza, M. and Pelosi, P., 1990. Electroantennogram responses of five lepidoptera species to 26 general odourants. Journal of Insect Physiology 36, pp. 619-624.

Waladde, S. M., 1982. Tip recording from ixodid tick olfactory sensilla-responses to tick related odours. Journal of Comparative Physiology 148, pp. 411-418.

Yaws, C. L., 1994. Handbook of Vapor Pressure, Gulf Publishing, Houston, TX (4 volumes).

Zhu, J. W., Cosse, A. A., Obrycki, J. J., Boo, K. S., and Baker, T. C., 1999. Olfactory reactions of the twelve-spotted lady beetle, Coleomegilla maculata, and the green lacewing, Chrysoperla carnea, to semiochemicals released from their prey and host plant: electroantennogram and behavioural responses. Journal of Chemical Ecology 25, pp. 1163-1177. 